\title{
Clinical Pharmacist Faculty Contribution to Evidence- Based Medicine and Milestones
}

Jean Moon, PharmD, BCACP | Jody Lounsbery, PharmD, BCPS | Amie Hall, PharmD | Stephanie L. Ballard, PharmD, BCPS | Nicholas Owens, PharmD, BCPS | Andrew Slattengren, DO

Published: 8/8/2017| DOI: 10.22454/PRiMER.2017.393370

\section{Abstract}

Introduction: Family medicine residency programs (FMRPs) endeavor to meet evidence-based medicine (EBM) subcompetencies through the milestones project. Comprehensive descriptions of clinical pharmacists' contributions in teaching EBM within the context of residency are limited.

Methods: Over a study period of 2 months, clinical pharmacists across five FMRPs in four states were invited to track their interactions with physician residents. EBM resources, skills, and targeted milestone data were collected. Pharmacists also quantified their nonpatient care contributions to EBM.

Results: Of the 16 clinical pharmacists invited, $16(100 \%)$ participated in the October and $12(75.0 \%)$ in the March collection period. A total of 598.9 half days over 2 months (42 working days) of available teaching time were reported. The tracking tool captured 1,253 EBM teaching encounters with a total average of 2.1 encounters per half day. Of those encounters, point-of-care references were most commonly used (63.7\%) and "apply" was the most common EBM skill taught (83.8\%). The most commonly tracked milestone was Medical Knowledge 2 (75.3\%) at Level 2 . Nine out of 10 faculty pharmacists included in this study reported performing the following roles: preceptor (100\%), lecturer (89.9\%), provider $(77.8 \%)$, expert/consultant $(77.8 \%)$, health care team $(66.7 \%)$, and other $(11.1 \%)$. Faculty pharmacists also reported directly evaluating milestones for physician residents through: committee work $(44.4 \%)$, resident evaluations $(77.8 \%)$, and rotation evaluations (77.8\%).

Conclusions: As FMRPs strive to meet ACGME EBM-related competencies, clinical pharmacists across multiple sites demonstrated contributions to teaching EBM in medical resident education. Using a nonphysician faculty for this purpose may provide an example for other FMRPs.

\section{Introduction}

The introduction of Accreditation Council for Graduate Medical Education (ACGME) Milestones Project in 2013 defined progressive, rigorous educational targets for family medicine residency programs (FMRPs). These new competencies integrated several milestones focused on evidence-based medicine (EBM), a fundamental approach to finding, appraising, and using evidence for medical decision making. ${ }^{1-3}$

Incorporating EBM into everyday practice is challenging. In an observational study by Ely and colleagues, family medicine physicians did not immediately answer $64 \%$ of the clinical questions encountered. ${ }^{4} \mathrm{~A}$ review by van Dijk and colleagues showed that residents similarly identify time and searching skills as barriers to using EBM in practice. ${ }^{5}$ Residents additionally encountered negative influences by clinical supervisors, lack of role models, and practical and institutional barriers (eg, resident shortage, lack of funding). These findings, in conjunction with the EBM milestones, challenge FMRPs to find additional ways to support EBM training. 
Pharmacists teach in approximately $30 \%$ of FMRPs, serving in various roles such as clinical resources, patient care providers, preceptors, evaluators, and program administrators. ${ }^{6-14}$ Understanding how pharmacist faculty contribute to teaching EBM within FMRPs may provide examples to other FMRPs, while further defining the pharmacist faculty role. ${ }^{11,15}$ The aim of this project is to quantify pharmacist teaching and evaluation of EBM in the context of the ACGME Milestones across multiple FMRPs.

\section{Methods}

\section{Participating Sites}

Five FMRPs, with integrated pharmacists and within four health systems across the country, participated in this project. This included pharmacists across five inpatient and seven outpatient sites, with ten faculty and six resident pharmacists.

\section{Data Collection}

A tracking tool was developed and piloted for usability to capture pharmacist EBM teaching encounters occurring during patient care. Published work by pharmacist faculty was reviewed and the tracking tool was created. ${ }^{11}$ Since both pharmacy residents and faculty are integrated into patient care delivery within these sites, each tracked their teaching encounters. Furthermore, pharmacy residents in FMRPs have the added responsibility to provide interprofessional teaching, and were included in this portion of the data collection. The tool tracked the evidence source and the EBM skill taught to the resident. ACGME subcompetencies with specific levels were also targeted. Pharmacists entered data into an internet-based survey instrument (Qualtrics, Provo, UT). Data collection occurred over two month-long periods (October 2014 and March 2015).

\section{Interview Survey}

Pharmacist faculty were surveyed to collect the other EBM contributions occurring outside of direct patient care. ${ }^{17}$ Pharmacist faculty recorded their roles, approximation of effort, funding for position, and clinical and educational services provided that contribute to EBM. The survey was delivered via an internet-based survey instrument (Qualtrics, Provo, UT) in March 2015.

\section{Data Analysis}

All statistical analysis was conducted using SAS 9.3 (SAS Institute Inc., Cary, NC). Data from the interview survey were examined for recurring themes. Differences of greater than $10 \%$ were determined to be relevant. The project was reviewed and approved by the Institutional Review Boards at Spartanburg Regional Healthcare System, and determined to be exempt from review at Mercy Medical Center and St Luke's Hospital, the University of Minnesota, and the University of Pittsburgh.

\section{Results}

\section{EBM Encounters}

Clinical pharmacists reported being available for a total of 598.8 half days over a 2-month period (42 working days). Specifically, 16 (100\%) pharmacists in October and 12 (75.0\%) in March reported having available teaching time. A total of 1,253 EBM teaching encounters (mean 2.1 per half day) were captured (Table 1). Table 2 shows Level 2 was the most frequent set of milestones taught.

Graduate year 2 (G2) learners were more associated with the EBM skill "ask" (35.2\%) than their graduate year 1 (G1) $(19.7 \%)$ and graduate year 3 (G3) (22.0\%) colleagues. Pharmacists taught the Medical Knowledge-2 (MK-2) subcompetency Level 3 set of milestones less frequently to G2 (28.4\%) compared to G1 (37.6\%) or G3 (38.1\%) learners.

\section{Interview Survey}


Nine out of 10 pharmacist faculty responded to the survey. Pharmacist faculty reported providing the following FMRP roles: preceptor (100\%), lecturer (89.9\%), provider (77.8\%), expert/consultant $(77.8 \%)$, health care team $(66.7 \%)$, and other (11.1\%). Participation in various educational services included lecturer (89.9\%), curricular assessment (77.8\%), curricular development (66.7\%), direct instruction of journal club (66.7\%), and offering an EBMspecific rotation (66.7\%). Funding sources for pharmacists' salaries ranged from $46.7 \%$ paid from the clinic or institution, $6.7 \%$ from the school of medicine, $13.3 \%$ from the college of pharmacy, and $25.0 \%$ from the FMRP. Pharmacists reported providing direct evaluation of competencies for physician residents by: committee work (44.4\%), end of rotation evaluation $(77.8 \%)$ and other resident evaluations $(77.8 \%)$.

\section{Discussion}

Pharmacists relied mostly on point-of-care resources, expert opinion, and guidelines as their evidence provided for EBM. Expert opinion is considered to be a low level of evidence, similar to a case series, compared to primary literature and tertiary sources. ${ }^{18}$ The frequent use of expert opinion is not unexpected as the rate is similar to previously published results, and $77.8 \%$ of these faculty pharmacists selected expert/consultant as their role. ${ }^{11}$ Also, pharmacists may be providing higher level evidence, but selected expert opinion if they did not direct learners to the specific EBM resource.

Pharmacists tracked the EBM skill "apply" most commonly, and "appraise" the least. This likely reflects the tracking tool design, since it only captured those encounters occurring with patient care, and not during activities occurring in the other faculty roles. The "appraise" skill may be better captured during non-patient care activities such as journal club, where $55.6 \%$ of pharmacists reported facilitating.

Pharmacists taught MK-2 more than any of the other targeted subcompetencies, and may correspond to the tracking of EBM teaching during direct patient care encounters. Pharmacists coded Practice-based Learning and Improvement 2 (PBLI-2) the least. As this subcompetency mainly addresses self-directed learning and personal reflection, it may be difficult to capture during patient care.

Although pharmacists taught to all levels of the targeted subcompetencies, they most commonly taught to Level 2 . While pharmacists teach to the various levels, this data does not reflect what level the resident physicians achieved.

Our results show that pharmacists participate in evaluating competencies in a variety of ways. Some variation may be reflective of the source of pharmacist funding and time dedicated for committees (eg, Clinical Competency Committee). Standards for the education and residency training of pharmacists includes educational outcomes and competencies that embrace EBM skills. ${ }^{19,20}$ However, there is limited information regarding how pharmacists compare to physician or other faculty in teaching EBM or the physicians' perception of pharmacist contributions to EBM within FMRPs. These may be future areas of study.

Although this represented a multicentered cohort from across the country, only five self-selected programs and 16 clinical pharmacists were invited to participate. This does not represent all pharmacists within FMRPs. Due to varying schedules, some of the clinical pharmacists reported not being available for teaching during the study period. Our cohort included pharmacists who practiced only outpatient, only inpatient, and combinations of both. The differences in setting and funding represent the diversity of pharmacists in FMRPs across the nation.

Data collection occurred in October and March, attempting to capture knowledge and progression throughout the year. Further research should include resident physician retention of the competencies attained from interactions with clinical pharmacists.

\section{Conclusion}

Our data demonstrates that clinical pharmacists are providing evidence and teaching EBM skills in the context of the ACGME competencies across multiple sites in FMRPs. Physician residents experience unique barriers to using EBM in everyday practice, and this study provides an example of how nonphysician educators, such as pharmacists, 
can enhance the teaching of EBM within FMRPs.

\section{Tables and Figures}

Table 1: Primary Outcome Measures: Reference Used, Skill Taught, and ACGME Subcompetency Utilization in Pharmacist Teaching

\begin{tabular}{|c|c|}
\hline EBM Outcome Measure & 1,253 Encounters $n(\%)$ \\
\hline \multicolumn{2}{|c|}{ EBM Reference Used } \\
\hline Guideline & $433(34.6)$ \\
\hline Primary literature & $156(12.5)$ \\
\hline Tertiary & $231(18.4)$ \\
\hline Point-of-care & $798(63.7)$ \\
\hline Expert & $708(56.5)$ \\
\hline \multicolumn{2}{|c|}{ EBM Skill Taught } \\
\hline Ask & $306(24.4)$ \\
\hline Acquire & $480(38.3)$ \\
\hline Appraise & $264(21.1)$ \\
\hline Apply & $1050(83.8)$ \\
\hline \multicolumn{2}{|c|}{ ACGME Subcompetency } \\
\hline $\begin{array}{l}\text { Medical Knowledge (MK-2): } \\
\text { Applies critical thinking skills in patient care }\end{array}$ & $944(75.3)$ \\
\hline $\begin{array}{l}\text { Systems-based Practice (SBP- } 1 \text { ): } \\
\text { Provides cost-conscious medical care }\end{array}$ & $227(18.1)$ \\
\hline $\begin{array}{l}\text { Systems-based Practice (SBP-2): } \\
\text { Emphasizes patient safety }\end{array}$ & $249(19.9)$ \\
\hline $\begin{array}{l}\text { Practice-based Learning and Improvement (PBLI-1): } \\
\text { locates, appraises, and assimilates evidence from scientific } \\
\text { studies related to the patient's health problems }\end{array}$ & $292(23.3)$ \\
\hline $\begin{array}{c}\text { Practice-based Learning and Improvement (PBLI-2): } \\
\text { Demonstrates self-directed learning }\end{array}$ & $149(11.9)$ \\
\hline $\begin{array}{l}\text { Patient Care (PC-2): } \\
\text { Cares for patients with chronic conditions }\end{array}$ & $391(31.2)$ \\
\hline
\end{tabular}


Table 2: Level of ACGME Subcompetency Taught by Pharmacist for Encounters $(n=1,253)$

\begin{tabular}{|c|c|c|c|c|c|}
\hline Subcompetency & $\begin{array}{l}\text { Level } 1 \\
\text { n }(\%)\end{array}$ & $\begin{array}{l}\text { Level } 2 \\
\text { n }(\%)\end{array}$ & $\begin{array}{l}\text { Level } 3 \\
\text { n }(\%)\end{array}$ & $\begin{array}{l}\text { Level } 4 \\
\text { n }(\%)\end{array}$ & $\begin{array}{l}\text { Level } 5 \\
\text { n }(\%)\end{array}$ \\
\hline $\begin{array}{l}\text { Medical Knowledge (MK-2): } \\
\text { Applies critical thinking skills in patient care }\end{array}$ & $\begin{array}{c}97 \\
(7.7)\end{array}$ & $\begin{array}{l}328 \\
(26.2)\end{array}$ & $\begin{array}{c}344 \\
(27.5)\end{array}$ & $\begin{array}{l}86 \\
(6.9)\end{array}$ & $\begin{array}{l}89 \\
(7.1)\end{array}$ \\
\hline $\begin{array}{l}\text { Systems-based Practice (SBP-1): } \\
\text { Provides cost-conscious medical care }\end{array}$ & $\begin{array}{c}4 \\
(0.3)\end{array}$ & $\begin{array}{l}67 \\
(5.3)\end{array}$ & $\begin{array}{c}130 \\
(10.4)\end{array}$ & $\begin{array}{c}15 \\
(1.2)\end{array}$ & $\begin{array}{c}11 \\
(0.9)\end{array}$ \\
\hline $\begin{array}{l}\text { Systems-based Practice (SBP-2): } \\
\text { Emphasizes patient safety }\end{array}$ & $\begin{array}{c}37 \\
(3.0)\end{array}$ & $\begin{array}{c}187 \\
(14.9)\end{array}$ & $\begin{array}{c}11 \\
(0.9)\end{array}$ & $\begin{array}{c}11 \\
(0.9)\end{array}$ & $\begin{array}{l}3( \\
0.2)\end{array}$ \\
\hline $\begin{array}{c}\text { Practice-based Learning and Improvement (PBLI-1): } \\
\text { locates, appraises, and assimilates evidence from } \\
\text { scientific studies related to the patient's health } \\
\text { problems }\end{array}$ & $\left(\begin{array}{c}1 \\
(0.1)\end{array}\right.$ & $\begin{array}{c}75 \\
(6.0)\end{array}$ & $\begin{array}{c}172 \\
(13.7)\end{array}$ & $\begin{array}{c}42 \\
(3.4)\end{array}$ & $\begin{array}{c}2 \\
(0.2)\end{array}$ \\
\hline $\begin{array}{c}\text { Practice-based Learning and Improvement (PBLI-2): } \\
\text { Demonstrates self-directed learning }\end{array}$ & $(0.1)$ & $\begin{array}{c}66 \\
(5.3)\end{array}$ & $\begin{array}{c}0 \\
(0)\end{array}$ & $\begin{array}{l}71 \\
(5.7)\end{array}$ & $\begin{array}{c}11 \\
(0.9)\end{array}$ \\
\hline $\begin{array}{c}\text { Patient Care (PC-2): } \\
\text { Cares for patients with chronic conditions }\end{array}$ & $\begin{array}{c}6 \\
0.5)\end{array}$ & $\begin{array}{c}243 \\
(19.4)\end{array}$ & $\begin{array}{c}85 \\
(6.8)\end{array}$ & $\begin{array}{c}13 \\
(1.0)\end{array}$ & $\begin{array}{c}44 \\
(3.5)\end{array}$ \\
\hline $\begin{array}{c}\text { Total } \\
(n=2,252)^{*}\end{array}$ & $\begin{array}{c}146 \\
(6.5)\end{array}$ & $\begin{array}{c}966 \\
(42.9)\end{array}$ & $\begin{array}{c}742 \\
(32.9)\end{array}$ & $\begin{array}{c}238 \\
(10.6)\end{array}$ & $\begin{array}{c}160 \\
(7.1)\end{array}$ \\
\hline
\end{tabular}

*In the 1,253 encounters, 2,252 subcompetencies taught.

\section{Acknowledgements}

Portions of this article were presented at the 2015 Society of Teachers of Family Medicine Annual Spring Conference.

\section{Corresponding Author}

Jean Moon, PharmD, BCACP

7-103 Weaver-Densford Hall 308 Harvard St. SE Minneapolis, MN 55455. 612-730-7212. Fax: 612-625-9931.

jmoon@umn.edu

\section{Author Affiliations}

Jean Moon, PharmD, BCACP - University of Minnesota College of Pharmacy

Jody Lounsbery, PharmD, BCPS - University of Minnesota College of Pharmacy

Amie Hall, PharmD - Family Health Clinic, Eglin Air Force Base, Florida

Stephanie L. Ballard, PharmD, BCPS - University of Pittsburgh Medical Center, Shadyside Family Medicine Residency Nicholas Owens, PharmD, BCPS - Philadelphia College of Pharmacy

Andrew Slattengren, DO - University of Minnesota Medical School, North Memorial Family Medicine Residency

\section{References}

1. Shaneyfelt T, Baum KD, Bell D, Feldstein D, Houston TK, Kaatz S, Whelan C, Green M. Instruments for evaluating education in evidence-based practice: a systematic review. JAMA. 2006;296:1116-27. https://doi.org/10.1001/jama.296.9.1116.

2. Accreditation Council for Graduate Medical: Milestones. http://www.acgme.org/acgmeweb/tabid /430/ProgramandInstitutionalAccreditation/NextAccreditationSystem/Milestones.aspx. Accessed March 31, 2015.

3. Accreditation Council for Graduate Medical Education and American Board of Family Medicine. The family medicine milestone project (September 2013). http://www.acgme-nas.org/assets/pdf/Milestones 
/FamilyMedicineMilestones.pdf. Accessed March 31, 2015.

4. Ely JW, Osheroff JA, Ebell MH, et al. Analysis of questions asked by family physicians regarding patient care. Western Journal of Medicine. 2000;172(5):315-319.

https://doi.org/10.1136/ewjm.172.5.315.

5. van Dijk N, Hooft L, Wieringa-de Waard M. What are the barriers to residents' practicing evidence-based medicine? A systematic review. Acad Med. 2010 Jul;85(7):1163-70.

https://doi.org/10.1097/ACM.0b013e3181d4152f.

6. Love DW, Hodge NA, Foley WA. The clinical pharmacist in a family practice residency program. J Fam Pract. 1980;10:67-72.

7. Johnston TS, Heffron WA. Clinical pharmacy in family practice residency programs. J Fam Pract. 1981;13:91-4.

8. Shaughnessy AF, Hume AL. Clinical pharmacists in family practice residency programs. J Fam Pract 1990;31(3):305-9.

9. Whelan AM, Burge F, Munroe K: Pharmacy services in family medicine residencies. Survey of clinics associated with Canadian residency programs. Can Fam Physician. 1994;40:468-471.

10. Dickerson L, Denham A, Lynch $T$. The state of clinical pharmacy practice in family practice residency programs. Fam Med. 2002;34(9):653-7.

11. Ables A. The Clinical pharmacist as a preceptor in a family practice residency training program. Fam Med. 2002;34(9):658-62.

12. Bazaldua O, Ables AZ, Dickerson LM, Hansen L, Harris I, Hoehns J, Jackson E, Kraus C, Mayville H, Saseen JJ. Suggested guidelines for pharmacotherapy curricula in family medicine residency training: recommendations from the society of teachers of family medicine group on pharmacotherapy. Fam Med. 2005;37(2):99-104

13. Dolovich L, Pottie K, Kaczorowski J, Farrell B, Austin Z, Rodriguez C, Gaebel K, Sellors C. Integrating family medicine and pharmacy to advance primary care. Therapeutics Clin Pharm \& Thera. 2008;83(6):913-917. https://doi.org/10.1038/clpt.2008.29.

14. Jorgenson D, Muller A, Whelan AM. Pharmacist educators in family medicine residency programs: a qualitative analysis. BMC Medical Education. 2012;12:74.

https://doi.org/10.1186/1472-6920-12-74.

15. Slawson DC, Shaughnessy AF. Teaching information mastery: creating informed consumers of medical information. J Am Board Fam Pract. 1999;12:444-449.

https://doi.org/10.3122/jabfm.12.6.444.

16. Moon JY, Lounsbery JL, Hall A, Slattengren A. EBM Pharmacist Tracking Tool. Retreived from the STFM Resource Library: http://resourcelibrary.stfm.org/viewdocument/ebm-pharmacist-trackingtool?CommunityKey=2751b51d-483f-45e2-81de-4faced0a290a. Accessed 2016.

17. Moon JY, Lounsbery JL, Hall A, Slattengren A. EBM Pharmacist Survey. Retrieved from the STFM Resource Library: http://resourcelibrary.stfm.org/viewdocument/ebm-pharmacist-trackingtool?CommunityKey=2751b51d-483f-45e2-81de-4faced0a290a. Accessed 2016.

18. Burns PB, Rohrich RJ, Chung KC. The levels of evidence and their role in evidence-based medicine. Plast Reconstr Surg. $2011 \mathrm{Jul} ;$ 128(1): 305-310. https://doi.org/10.1097/PRS.0b013e318219c171.

19. Accreditation Council for Pharmacy Education. Accreditation standards and key elements for the professional program in pharmacy leading to the doctor of pharmacy degree. Effective: July 1, 2016. https://www.acpeaccredit.org/pdf/Standards2016FINAL.pdf. Accessed December 14, 2016.

20. American Society of Health-System Pharmacists. Required Competency Areas, Goals, and Objectives for Postgraduate Year One (PGY1) Pharmacy Residencies. http://www.ashp.org/DocLibrary/Residents/PGY1Required-Competency-Areas.pdf. Accessed December 14, 2016.

Copyright $@ 2017$ by the Society of Teachers of Family Medicine 